\title{
O PAPEL E O DISCURSO DOS ARQUITETOS EM PROJETOS PAISAGÍSTICOS URBANOS
}

\author{
THE ARCHITECT'S ROLE AND SPEECH ON URBAN LANDSCAPE PROJECTS
}

\author{
SAKATA, Francine
}

\section{RESUMO}

O artigo traz reflexões sobre a participação dos arquitetos na idealização e na implantação de projetos paisagísticos de grande porte no espaço urbano e sobre a forma como o discurso que motiva os arquitetos também se incorpora ao discurso político. $O$ texto foi feito a partir de entrevistas e levantamentos junto a órgãos públicos realizados sistematicamente entre 1994 e 2004 no âmbito do Projeto Quapá - Quadro do Paisagismo no Brasil e de um trabalho específico sobre projetos paisagísticos urbanos em São Luís, Salvador, Rio de Janeiro, São Paulo e Curitiba.

Palavras-chave: Projetos paisagísticos, programas políticos, city marketing.

\begin{abstract}
The author reflected about the participation of architects in the design conception and implementation of Urban landscapes as well as the way the speech that motivates their work is incorporated to political campaigns. The article is based on surveys and interviews systematically done at public institutions from 1994 thru 2004 as part of the Quapa Project (Brazilian Landscape Architecture Research Lab) and the author's study on Urban landscapes in São Luis, Salvador, Rio de Janeiro, São Paulo and Curitiba.
\end{abstract}

Key words: Landscape design, public programs, city marketing.

\section{Programas políticos com projetos paisagísticos}

A implantação de projetos paisagísticos de porte no espaço público envolve diversos agentes: a administração pública, escritórios de arquitetura ou consultores contratados, construtoras, concessionárias de infra-estrutura, a sociedade civil (ONGs, associações comerciais, empreendedores imobiliários, etc) e também a mídia. A participação destes agentes varia caso a caso e cada um tem o seu próprio discurso, ligado aos interesses da categoria.

Em projetos de grande visibilidade, é muito comum que o administrador em pessoa, prefeito ou governador, muitas vezes participe ativamente e imponha certas características aos projetos. Políticos definem programas de uso, estabelecem cronogramas e custos, selecionam os profissionais que farão os projetos e, finalmente, encomendam a estes profissionais os signos visuais que representarão sua administração.

Nos anos 1990 e 2000, prefeitos e governadores têm se esforçado em oferecer suas cidades e seus estados para montadoras de automóveis, fábricas nacionais ou multinacionais, shopping centers e cadeias de supermercados, a fim de atrair renda e empregos. Exibem as qualidades dos lugares através de imagens, slogans e índices como vantagens aos investidores.

Quando o chefe do poder executivo local se apresenta como "pai" de um programa de requalificação de espaços públicos com grande visibilidade, os diferentes órgãos da administração pública dialogam e cooperam entre si para as obras saírem a contento, o que é menos comum do que deveria ser no cotidiano das grandes capitais.

Mas os projetos de espaços públicos não dependem apenas da vontade do administrador. Há os outros participantes mencionados, o arcabouço institucional, a articulação entre as esferas 
governamentais de âmbito municipal, estadual e federal e há os recursos para respaldar os programas (ou a falta deles).

Em nosso estudo, em São Luís e em Salvador, foi o governo estadual que implantou os projetos paisagísticos de maior porte. Em Curitiba, São Paulo e no Rio de Janeiro foram as gestões municipais. A primeira justificativa apontada era ligada à arrecadação - no Rio de Janeiro diz-se que o Estado é "pobre" e o município é "rico"; no Maranhão, o Estado é "rico" e o município é "pobre", e assim por diante. Mas há questões fundiárias, jurisdições e articulações políticas entre outras condições.

O Programa Viva Bairro, em São Luís, e a reforma do Pelourinho, em Salvador, são exemplos de programas com projetos paisagísticos conduzidos em um quadro de disputas entre a administração estadual e a municipal e foram instrumentos de propaganda política da esfera de governo que os conduziu.

Viva Bairro qualificou praças nos bairros, um tipo de ação que costuma dar prestígio e que é conduzida pelas gestões municipais mas que, neste caso, não o foi. O Pelourinho foi objeto do desejo de prefeitos, governadores e até do Serviço do Patrimônio Histórico, órgão ligado à Presidência da República. Sua reforma acabou sendo conduzida pelo governo do Estado de forma veloz e radical, como símbolo da força para transformar qualquer coisa.

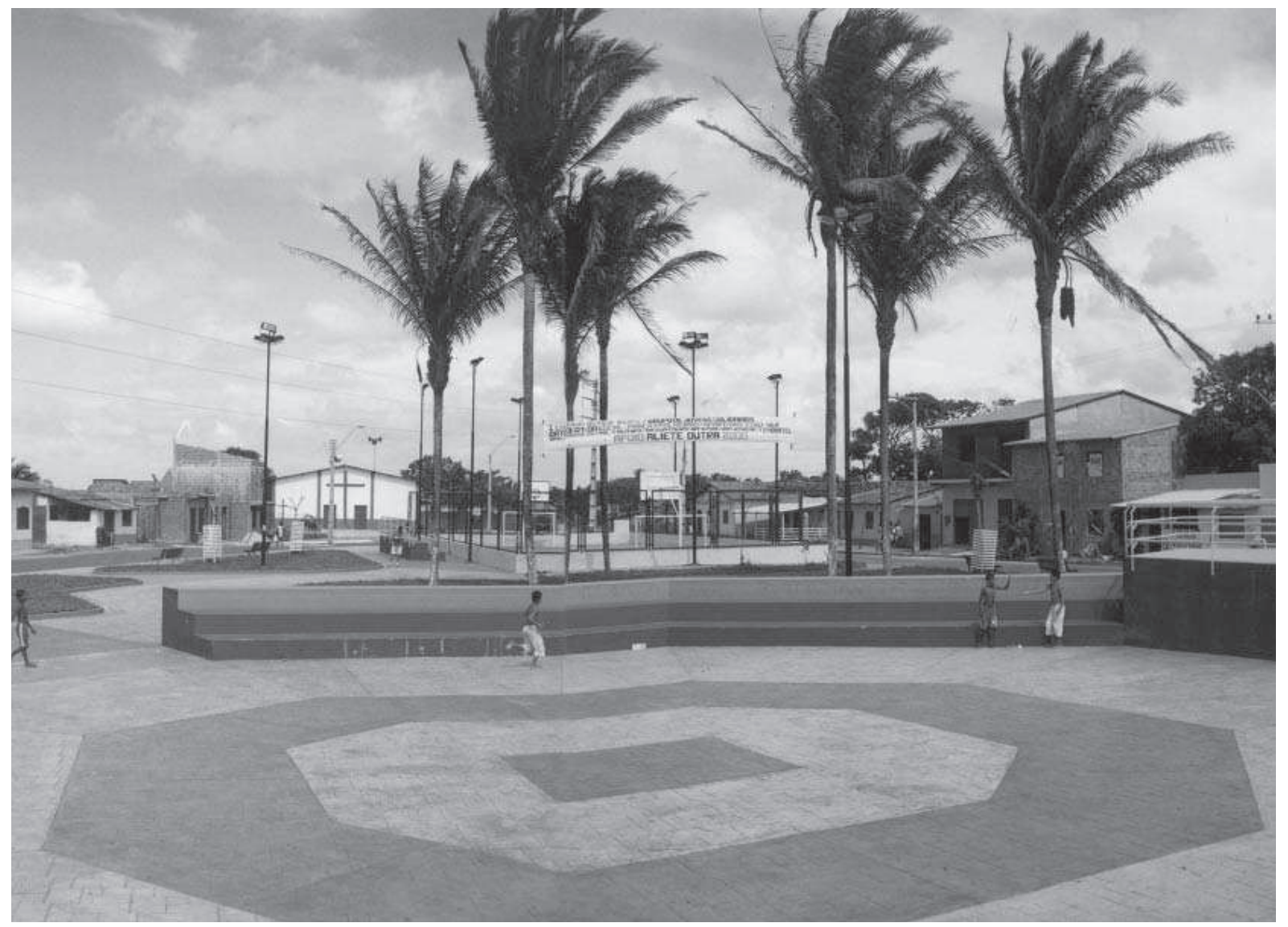

Figura 1: Viva Vila Embratel (nome da praça da Vila Embratel que foi requalificada pelo programa Viva Bairro). A grande qualidade deste programa foi não inventar espaços para a população se apropriar (e o turista ver), mas apenas tratar formalmente espaços que já eram apropriados pelas festas locais. O espaço foi considerado suporte para o espetáculo e não o espetáculo em si

Foto: Francine Sakata, Acervo Quapá/2003

Uma miríade de interesses é a realidade complexa que o arquiteto encontra quando se envolve em um projeto paisagístico de porte. Ele precisa intermediar os anseios de políticos e as necessidades reais da população. 


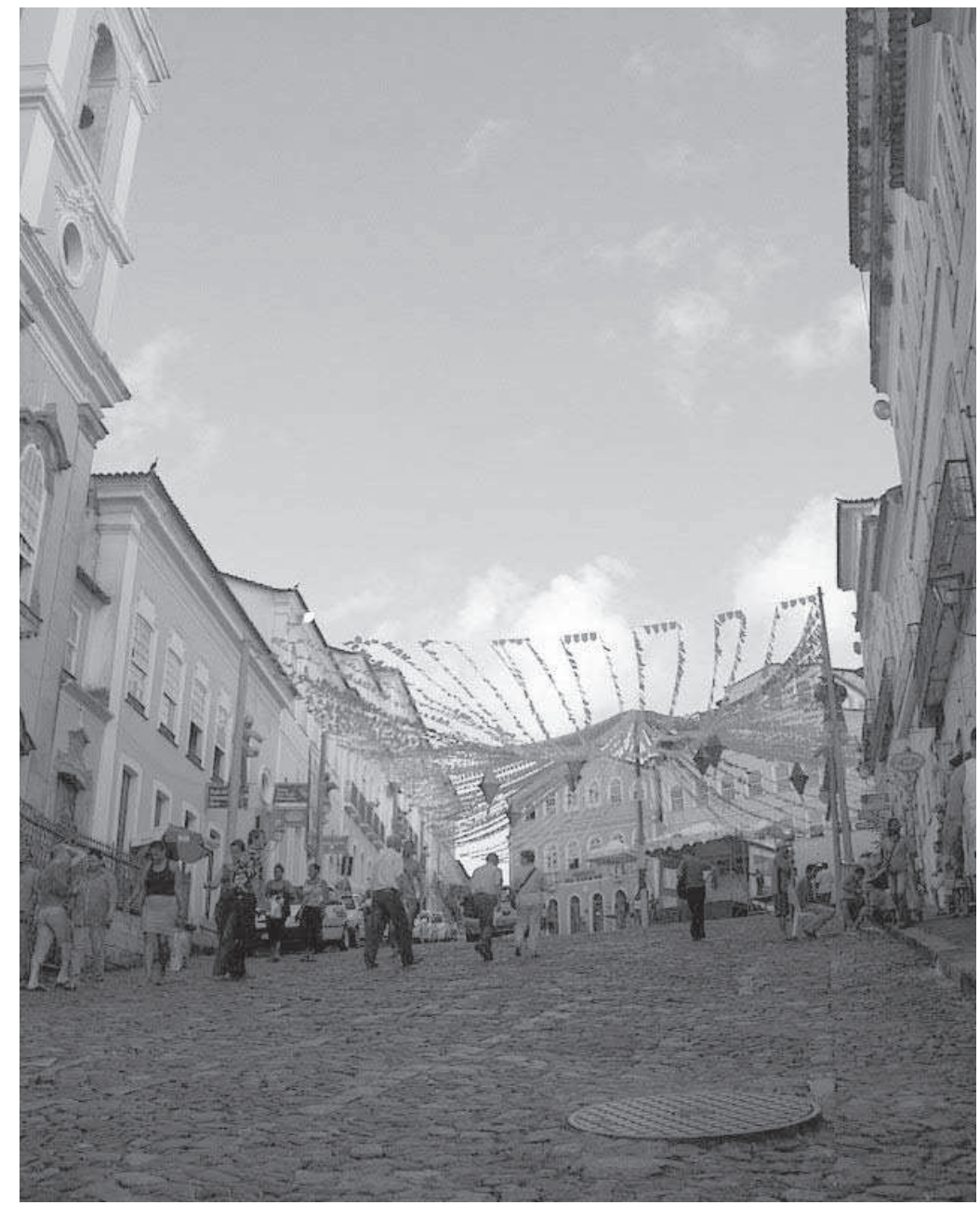

Figura 2: Pelourinho, em Salvador. Foi feito intenso uso da cenarização e da fantasia. Em que pesem críticas à forma como a intervenção foi conduzida, ela era necessária

Foto: Francine Sakata, Acervo Quapá/ 2004

\section{Formadores de políticas públicas}

Tanto para políticos como para arquitetos envolvidos no projeto de espaços públicos, a grande recompensa é o reconhecimento da sociedade. No entanto, políticos querem transmitir a imagem de que são preocupados com o bem-estar da população, ousados, inteligentes e bons administradores. Arquitetos esperam colocar em prática as idéias e os consensos que trazem de sua formação profissional.

Arquitetos são formadores de políticas públicas, seja quando fazem parte de órgãos do governo como quando são contratados para desenvolver projetos. Assim, seus valores passam a integram programas de governo e discursos políticos.

\section{Arquitetos, arquitetos paisagistas ou urbanistas}

Antes, um esclarecimento: neste texto todos aqueles com ofícios de urbanistas ou arquitetos paisagistas serão denominados arquitetos, genericamente. Via de regra, todos passaram pelo curso de arquitetura e urbanismo e não tiveram formações específicas na graduação de urban designers, planners ou arquitetos paisagistas, como ocorre nos Estados Unidos e na Europa.

Outra sobreposição corrente é feita entre os termos projeto paisagístico e desenho urbano. Esta falta de linhas demarcatórias claras pode derivar do fato dos profissionais que desempenham 
estas especialidades terem todos a mesma formação e atuarem de forma interdisciplinar. Mesmo nos maiores mercados de projetos (São Paulo e Rio de Janeiro), os arquitetos-de-formação precisam muitas vezes resolver questões de diferentes especializações.

Entre os profissionais que entrevistamos, estava o arquiteto Manoel Ribeiro, autor do projeto Favela-Bairro na Serrinha, no Rio de Janeiro. Antes do Favela-Bairro, ele havia desenvolvido projetos de planejamento integrado e regional no Serviço Federal e no Banco Nacional de Habitação - BNH. Depois, criou cenários para um dos grupos teatrais mais importantes de Portugal. No Favela-Bairro, à medida que buscava soluções espaciais que promovessem renda e emprego, sua participação transcendeu a do urbanista tradicional e se aproximou daquela dos agitadores culturais. Não havia fórmulas consagradas para transformar favelas em espaços da cidade e o trabalho interdisciplinar realizado por Manoel Ribeiro acabou se tornando um modelo.

Em São Luís, os arquitetos Geraldo Magela e Frederico Burnet, autores dos projetos do Programa Viva Bairro, dividiram-se entre o trabalho no escritório de arquitetura, no serviço público e na docência da Universidade Estadual do Maranhão. Ao mesmo tempo em que desenhavam espaços livres, criavam também igrejas e edifícios de apartamentos. Em São Luiz, todas estas atividades não impediram os arquitetos de trabalharem juntos com todas as comunidades para os quais estavam projetando.

Há também profissionais que têm se dedicado exclusivamente à arquitetura paisagística. Rosa Kliass (formada arquiteta e urbanista) foi responsável por projetos de desenho da paisagem por todo o país e tem se empenhado na formalização da categoria. Uma de suas ações foi a criação da Associação Brasileira dos Arquitetos Paisagistas, ABAP, em 1976, que atualmente compartilha esta missão.

A inexistência de cursos de nível superior especializados a até 2006 parece refletir esta prática profissional. Mas o fato destes cursos de graduação estarem sendo idealizados e discutidos demonstra que, ao longe, a especialização irá adquirir contornos mais claros.

\section{Quando o arquiteto faz o projeto e quando ele o propõe}

Duas etapas se distinguem nos programas: a primeira é a idealização da ação, que envolve a escolha das áreas e a definição das características gerais dos projetos. A segunda etapa é o projeto propriamente dito, realizado por arquitetos, geralmente contratados pelo poder público fora de seus quadros. Contratam-se profissionais "de mercado" para o desenvolvimento de projetos de maior visibilidade porque o que se espera são soluções novas, que proporcionem imagens de maior impacto.

A primeira etapa pode ter intenso ou até nenhum envolvimento de arquitetos. Nos programas que analisamos (em que os espaços públicos ocuparam posição central), os arquitetos tiveram grande participação na definição do que viria a ser a ação. O Rio Cidade é um exemplo de programa concebido por arquitetos oriundos do corpo técnico do Instituto Pereira Passos, coordenados pelo Secretário de Urbanismo, Luiz Paulo Conde, que depois se tornaria prefeito.

A primeira proposta para a revitalização do Centro Histórico de São Luís, que data de 1977, foi de um arquiteto, John Gisiger. Este projeto foi feito sem ter sido encomendado e, descoberto, foi absorvido pelo poder público e ganhou vida institucional.

Em Curitiba, os arquitetos, não os políticos, foram alardeados como os protagonistas na implantação de parques ao longo dos cursos d'água. Chegou a ser divulgada a imagem dos urbanistas como os inovadores e criativos responsáveis pelos feitos que deram a Curitiba posição de destaque no mundo. Este fato foi resultado da institucionalização do planejamento urbano que, por sua vez, foi fruto da estreita relação entre os urbanistas e os prefeitos, com 
destaque para a figura do prefeito-arquiteto Jaime Lerner, que teve três gestões à frente do poder municipal e duas do estadual.

Em Salvador, a influência dos arquitetos nas decisões sobre o que fazer e como, tanto no Pelourinho quanto nos parques ao longo da orla, ficou obscurecida pelos desmandos de administrações fortemente centralizadas e personalizadas. Em compensação, se o papel dos arquitetos foi reduzido na definição do modelo das intervenções, seu papel foi ampliado na criação de formas. Uma marca dos projetos de Salvador é justamente a visualidade que têm.

Mas, mesmo em Salvador, houve arquitetos que se encarregaram da tarefa de levar projetos aos políticos. Arquitetos que trabalham em órgãos ou empresas públicas muitas vezes podem assumir a primeira campanha de todas pelas quais passa um projeto ao tentar vender a idéia para o governador ou o prefeito. Para convencê-los de que o programa ou o projeto gerará a repercussão que interessa aos políticos, o arquiteto tem que identificar e criar as imagens que a obra poderá representar.

A condição ideal para um projeto ser levado adiante é quando agrada a um grande número de classes e pessoas. É interessante que se encaixe em variados discursos, que possa ser visto por muitos ângulos diferentes. Por exemplo: se o projeto protege um bosque, agrada aos ambientalistas. Se valoriza os terrenos, agrada à vizinhança e aos empreendedores imobiliários. Se tiver espaços para as crianças, agrada às mães. Se criar novos empregos, agrada os trabalhadores, e assim por diante.

O arquiteto Mario Bestetti, da Conder - Companhia de Desenvolvimento do Estado da Bahia, abraçou o projeto de recuperação do Parque São Lourenço, próximo à avenida suburbana, no setor pobre da cidade (que já havia recebido uma ação do poder público: a relocação de moradores de Alagados, uma favela sobre palafitas). O Parque São Lourenço possui cachoeiras e árvores sagradas para o candomblé e o arquiteto divulga que o Parque São Lourenço está para o candomblé assim como o Vaticano está para o catolicismo, uma comparação que cria uma primeira imagem para justificar a intervenção.

Reverter o estado de abandono deste parque é uma demanda antiga da população. $\bigcirc$ Banco Mundial sinalizou que poderia financiar a obra de requalificação do parque a partir de material reunido por uma $\mathrm{ONG}$ e o arquiteto então preparou um documento contendo as justificativas, as diretrizes e um projeto para o parque. O financiamento não foi concedido na ocasião mas Mario Bestetti insiste neste trabalho, certo de que ele se viabiliza se houver interesse político.

O projeto do Parque Metropolitano de Pituaçu foi desenvolvido pela Conder através de um processo semelhante. $\bigcirc$ arquiteto Wilson Andrade é considerado pelos funcionários da empresa como o "pai" do parque. Naturalmente, para a população, esta paternidade é do governador Antonio Carlos Magalhães (por décadas, a figura política mais poderosa de Salvador). Mas foi o arquiteto que elaborou estudos para o parque e levou a proposta ao governador. Diz-se que, quando o governador decidiu implantar o parque, não houve mais empecilhos: foram feitas leis, desapropriações e obras que consolidaram o parque.

Quando o governante assume a paternidade de um projeto e passa a vendê-lo na câmara, na imprensa e para a população, os argumentos que lhe foram fornecidos pelos arquitetos são utilizados em seu discurso. Os arquitetos emprestam sua linguagem para a elaboração das novas imagens.

A busca de projeção e competitividade da cidade para os negócios foi um dos argumentos que justificou a implantação das sucessivas fases do Programa Rio Cidade e do Favela-Bairro no Rio de Janeiro mas, na prática, os projetos (com exceção daqueles nos bairros famosos da Zona Sul) tratavam os bairros para o dia-a-dia do cidadão, disciplinando o tráfego e os ambulantes em benefício dos pedestres. 


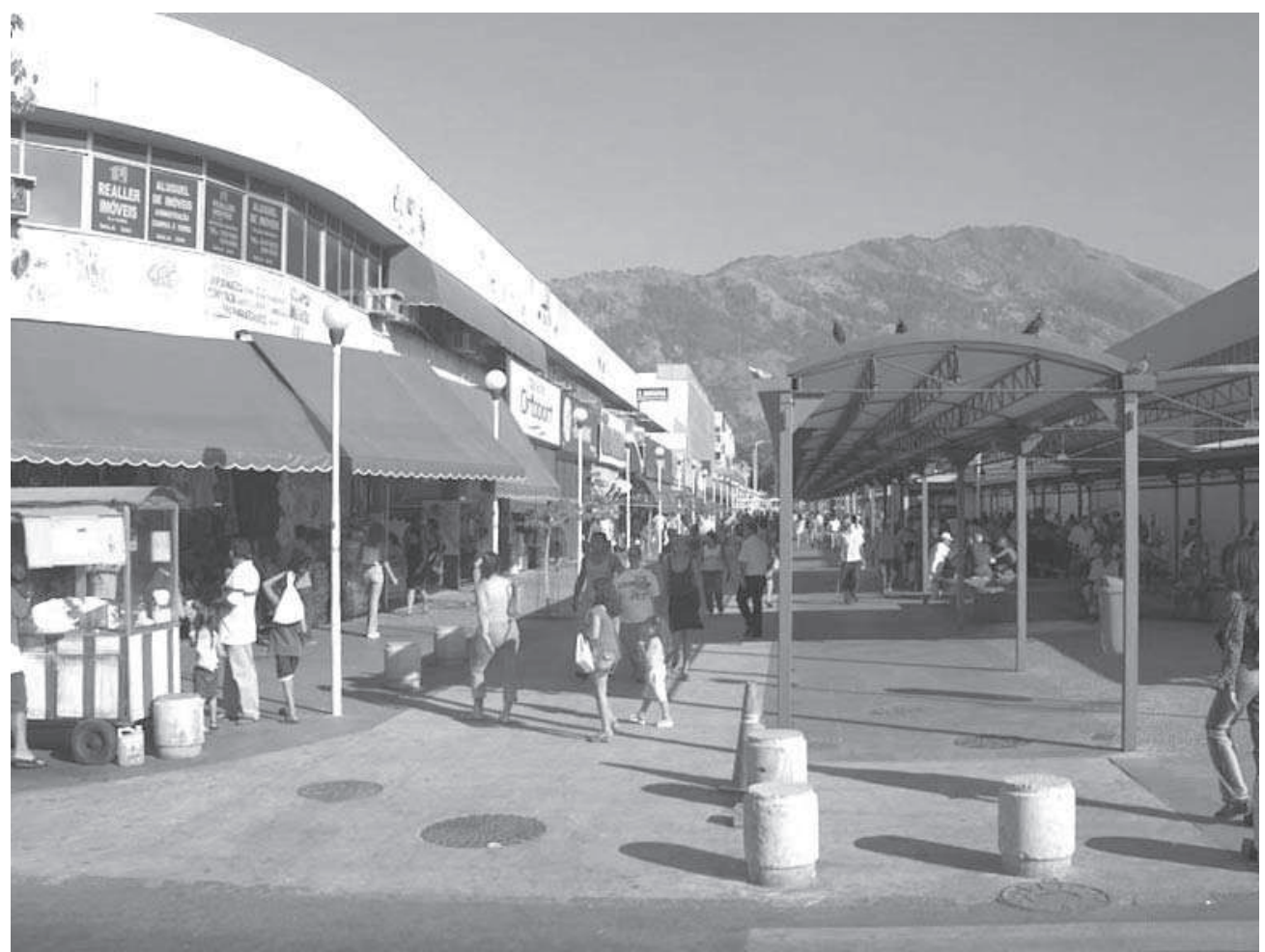

Figura 3: Rio Cidade Bangu

Foto: Francine Sakata, Acervo Quapá/2003

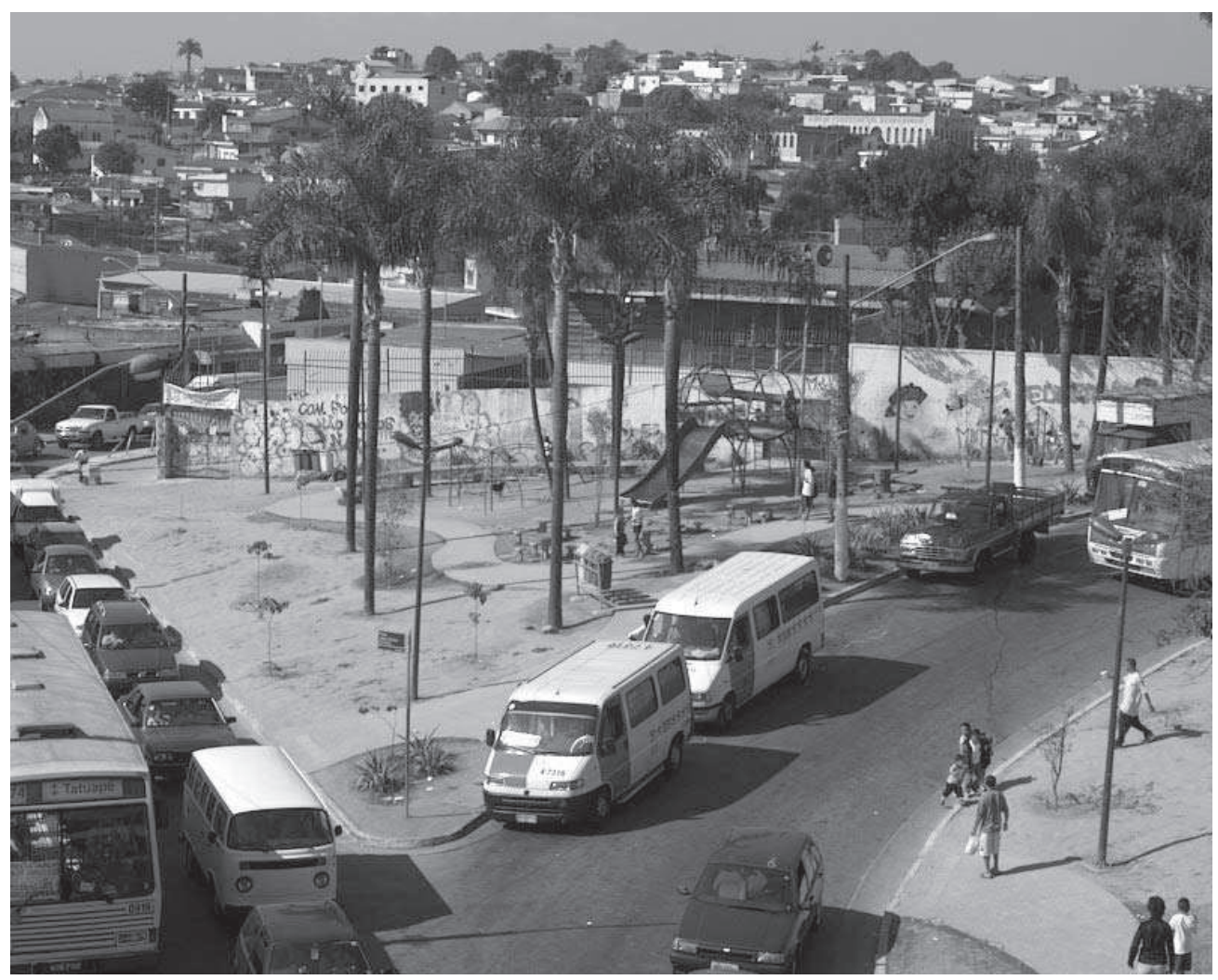

Figura 4: Praça próxima ao mercado de Guaianazes, em São Paulo

O Programa Centros de Bairro, ao requalificar praças, procurou compensar anos de políticas viaristas, mas não encontrou uma estrutura para gerir espaços um pouco mais sofisticados, nem canais de diálogo com a população. $\bigcirc$ resultado é que os arquitetos acertaram em muitos casos, mas não em todos Foto: Francine Sakata, Acervo Quapá/ 2004 


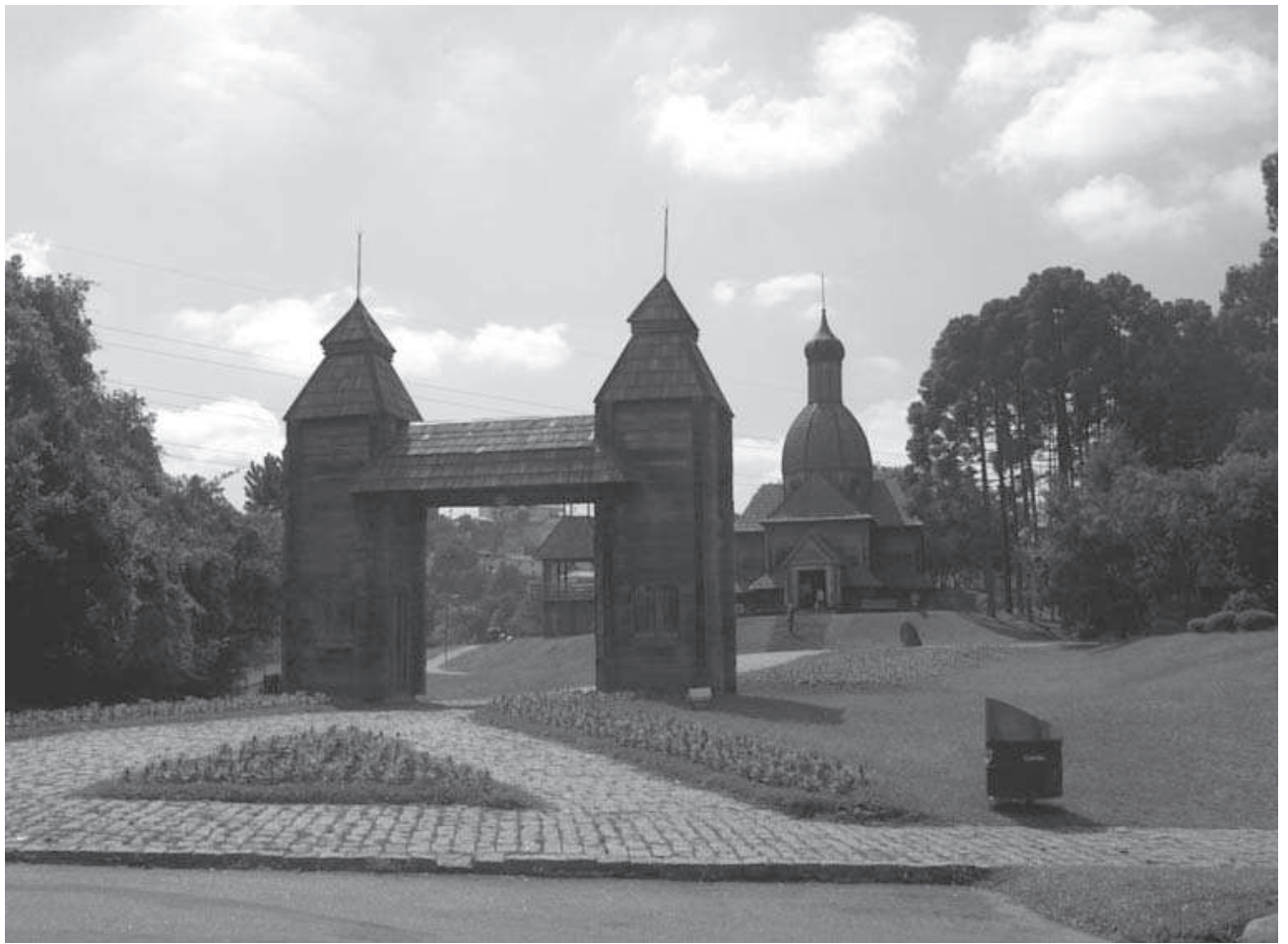

Figura 5: Parque Tingui, em Curitiba

Em Curitiba, equipamentos urbanos, novos museus e parques-atrações turísticas foram veiculados enfaticamente como imagens-síntese da cidade. Ainda que tendam a localizar-se na parte norte (e mais rica) da cidade, eles são intensamente apropriados por toda a população

Foto: Francine Sakata, Acervo Quapá/2004

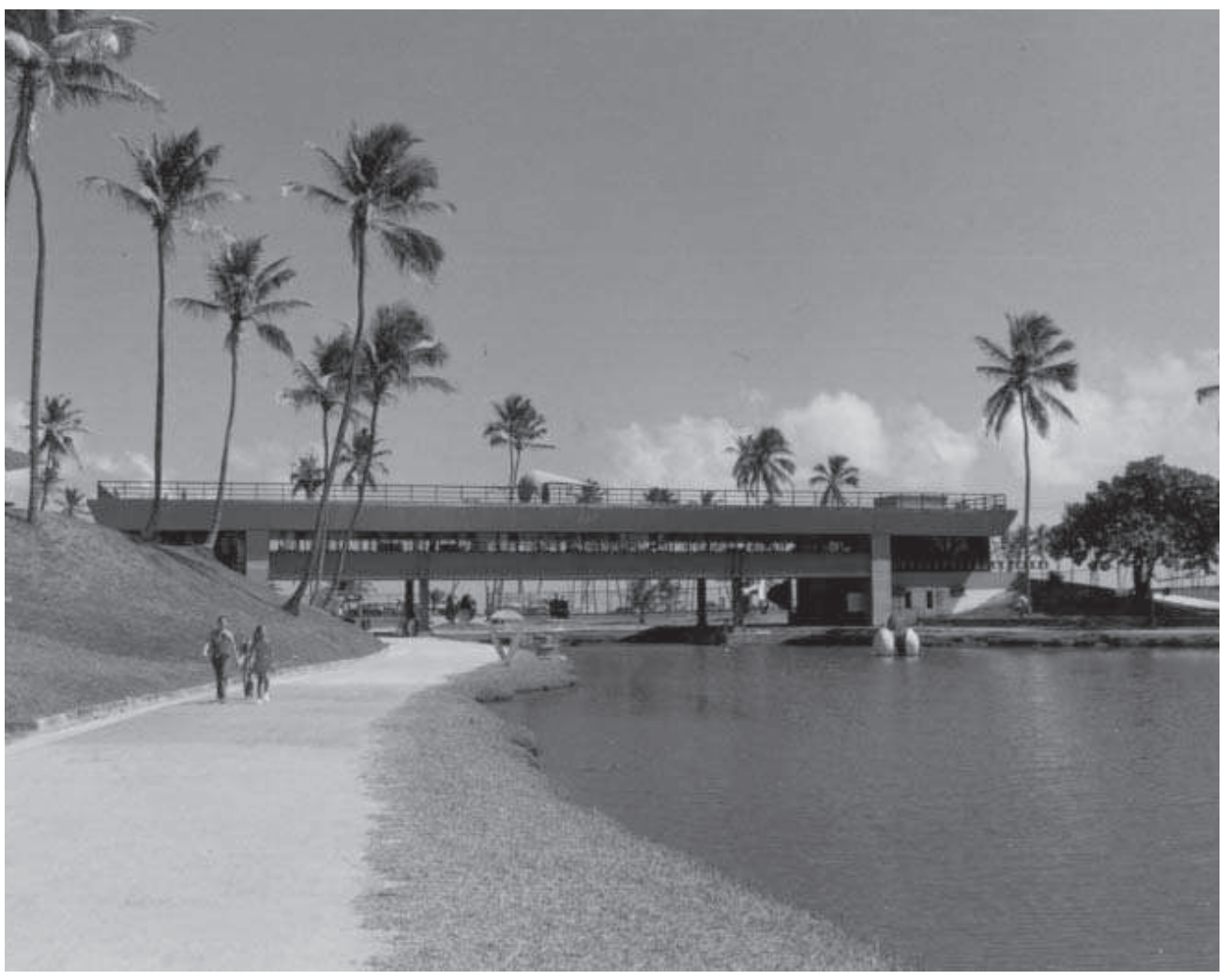

Figura 6: Parque Metropolitano de Pituaçu, em Salvador Foto: Francine Sakata, Acervo Quapá/2003 


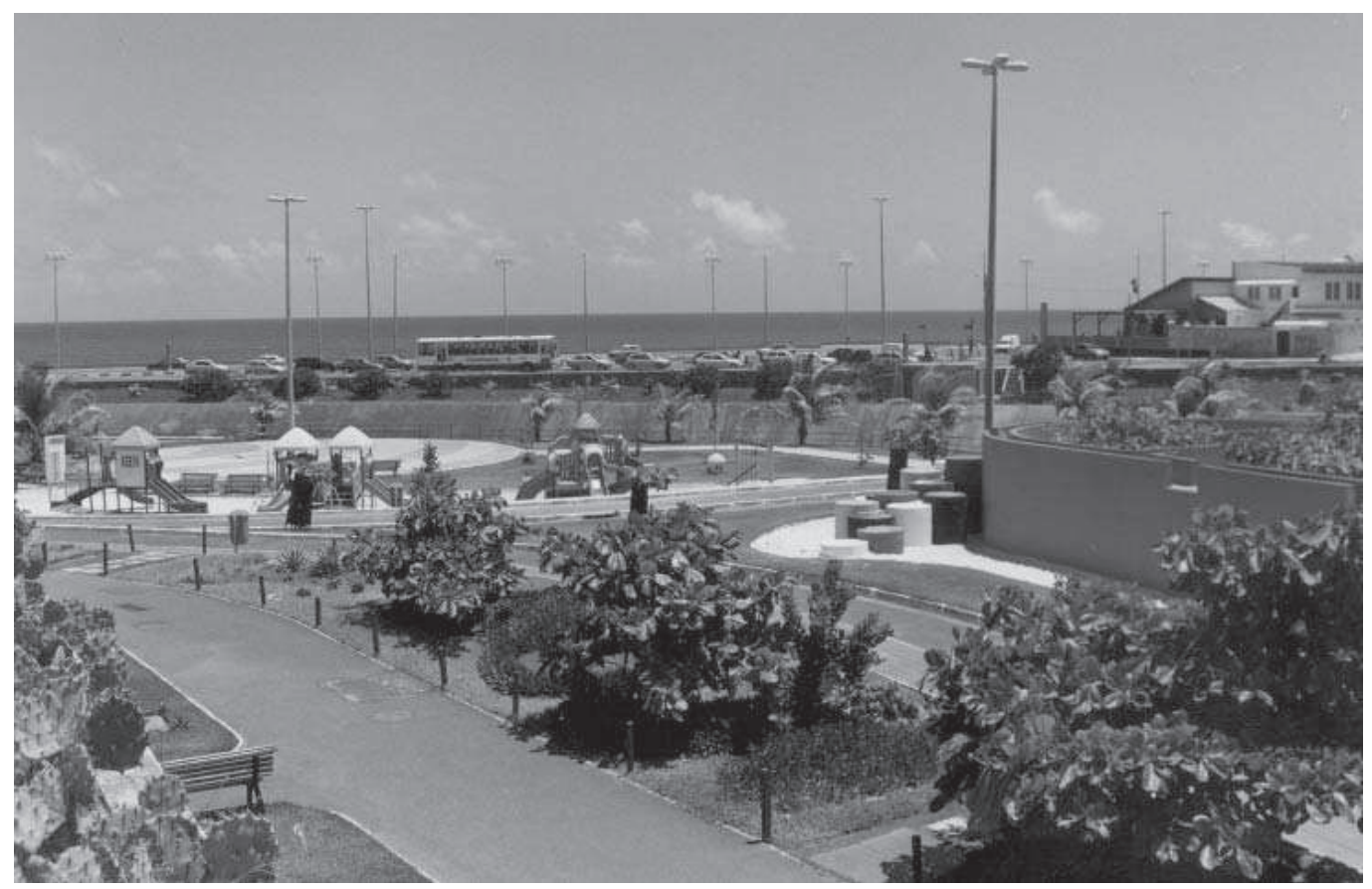

Figura 7: Parque Costa Azul, em Salvador

Em Salvador foi dado um tratamento sofisticado, com formas e alegorias quase carnavalescas, a fragmentos da cidade

Foto: Francine Sakata, Acervo Quapá/2003

\section{A cultura urbanística e o discurso político}

Os arquitetos propuseram para as capitais do país, ao longo dos anos 1990 e 2000, obras de requalificação dos espaços livres como forma de alavancar a dinamização das atividades e atrair novos usos. Nestes programas, a revitalização dos centros tradicionais (não apenas dos históricos) era sustentada pelo tratamento dos espaços livres - através de ações de desenho urbano e de cuidados com a limpeza pública e a manutenção.

Os espaços públicos foram valorizados como espaços privilegiados para o estabelecimento dos novos usos culturais e de entretenimento. Equipamentos como museus, teatros, centros culturais, conjuntos esportivos, centros de artesanato e cafés eram largamente recomendados para animar os espaços urbanos.

No centro do Rio de Janeiro, já no início dos anos 1980, os arquitetos buscaram criar condições para a revitalização de atividades culturais e recreativas propondo que fossem mantidos os suportes físicos de menor porte (sobrados) para o pequeno comércio varejista - livrarias, casas de chá, bares e restaurantes. Como pilares da revitalização imaginaram a cultura, o turismo, o comércio e a boemia. Mais tarde, se deram conta que incentivar o uso residencial seria interessante e também o fizeram. Esta intervenção do poder público a favor da humanização apresentou bons resultados.

Os arquitetos brasileiros, até os anos 1990, viveram uma dubiedade de princípios: seus ideais eram modernos (sua escola era o planejamento global, como seus zoneamentos e controles numéricos) mas eles enxergavam a necessidade de humanizar as decisões de gabinete. Os arquitetos estavam frustrados com a falta de aplicação dos planos diretores, com a pouca influência que a teoria acabava tendo na prática. Era preciso se aproximar da realidade.

As primeiras críticas ao planejamento global modernista surgiram na Europa já no final dos anos 1940 e valorizavam as ruas tradicionais, a diversidade de usos, a dinâmica urbana, os ornamentos, os significados simbólicos e lúdicos. 
O discurso modernista, que estava plenamente incorporado ao discurso político oficial, foi sendo substituído (com grande vigor nos anos 1990 em especial) pelo discurso plural que prega a valorização das ruas, dos centros históricos, das identidades locais, dos usos múltiplos e do desenho dos detalhes nos espaços da cidade.

A valorização dos centros e dos monumentos históricos já era discutida desde os tempos da criação do Instituto do Patrimônio Histórico e Artístico Nacional - Iphan, em 1937, mas é ao longo dos anos 1990 que obras de vulto e de grande visibilidade nos centros históricos são postas em prática, como as que foram feitas no Pelourinho, em São Luís e no Recife.

Estes novos valores, mais humanizados, vão de encontro e são apropriados pelo discurso oficial. As administrações públicas vinham buscando para si as imagens de que são preocupadas com a qualidade de vida do cidadão, que são mais democráticas e sociais que as anteriores.

Nem sempre certos os equipamentos culturais (como museus e teatros) podem ser usufruídos por todas as camadas da sociedade. Na prática, há grupos que estão fora do circuito de consumo de certos produtos culturais. Mas os arquitetos tendem a acreditar que o espaço público tratado pode promover requalificações sociais e, assim, compensar problemas de distribuição de renda.

Os equipamentos esportivos e de lazer têm público mais amplo. No Programa Favela-Bairro, os equipamentos de lazer foram utilizados como símbolos de status, de inclusão e de melhoria da qualidade de vida e justificaram o programa no imaginário da população. Na prática, muitos equipamentos não foram construídos mas foram importantes para impulsionar a ação.

O projeto urbano fornece material para a propaganda política. As áreas verdes e os espaços para lazer e cultura são os grandes sustentáculos das imagens. Mas há, no entanto, discursos que não saem do plano retórico. Preservação ambiental, sustentabilidade e participação popular são exemplos de expressões utilizadas para justificar os programas públicos e que muitas vezes não têm significado real.

Práticas sustentáveis, como o controle dos impactos da urbanização sobre os recursos ambientais, são muitas vezes contrárias a políticas de crescimento e renda de curto prazo e, por isso, não são adotadas, apenas citadas. A participação também tem sido mais um discurso para legitimar programas políticos.

Para os arquitetos, a utilização de imagens e de alegorias tem sido uma forma de viabilizar e atrair a atenção, os recursos e também novos usos. A prática mostra que as boas intenções se realizam e se perpetuam muito mais facilmente quando correspondem a benefícios políticos ou econômicos.

Entretanto as alegorias, quando de baixa qualidade e de difícil manutenção, desgastam-se muito rapidamente. Abandonadas e sujas, perdem a graça da surpresa e do lúdico e esvaziam-se de significado. No afã pelo reconhecimento, arquitetos tanto quanto políticos, tendem a eleger a novidade, a maior variedade de formas, materiais e cores e se esquecem que a qualidade do desenho e dos materiais e a facilidade de manutenção devem ser suas prioridades.

Em nome da prática saudável da arquitetura urbanística e paisagística, é preciso que haja uma relação contínua e verdadeira entre governantes e arquitetos propositivos. Como vimos com certa regularidade apenas em Curitiba e no Rio de Janeiro, os arquitetos (em escritórios ou em instituições de planejamento) devem fornecer material para os prefeitos, e os prefeitos devem recebê-los e demandar dos profissionais novas soluções para toda a cidade, levando-as adiante. Estas soluções devem ser continuamente discutidas e avaliadas, para que sejam corrigidos equívocos e efemeridades e para que o arquiteto, urbanista ou arquiteto paisagista dê respostas adequadas à realidade. 


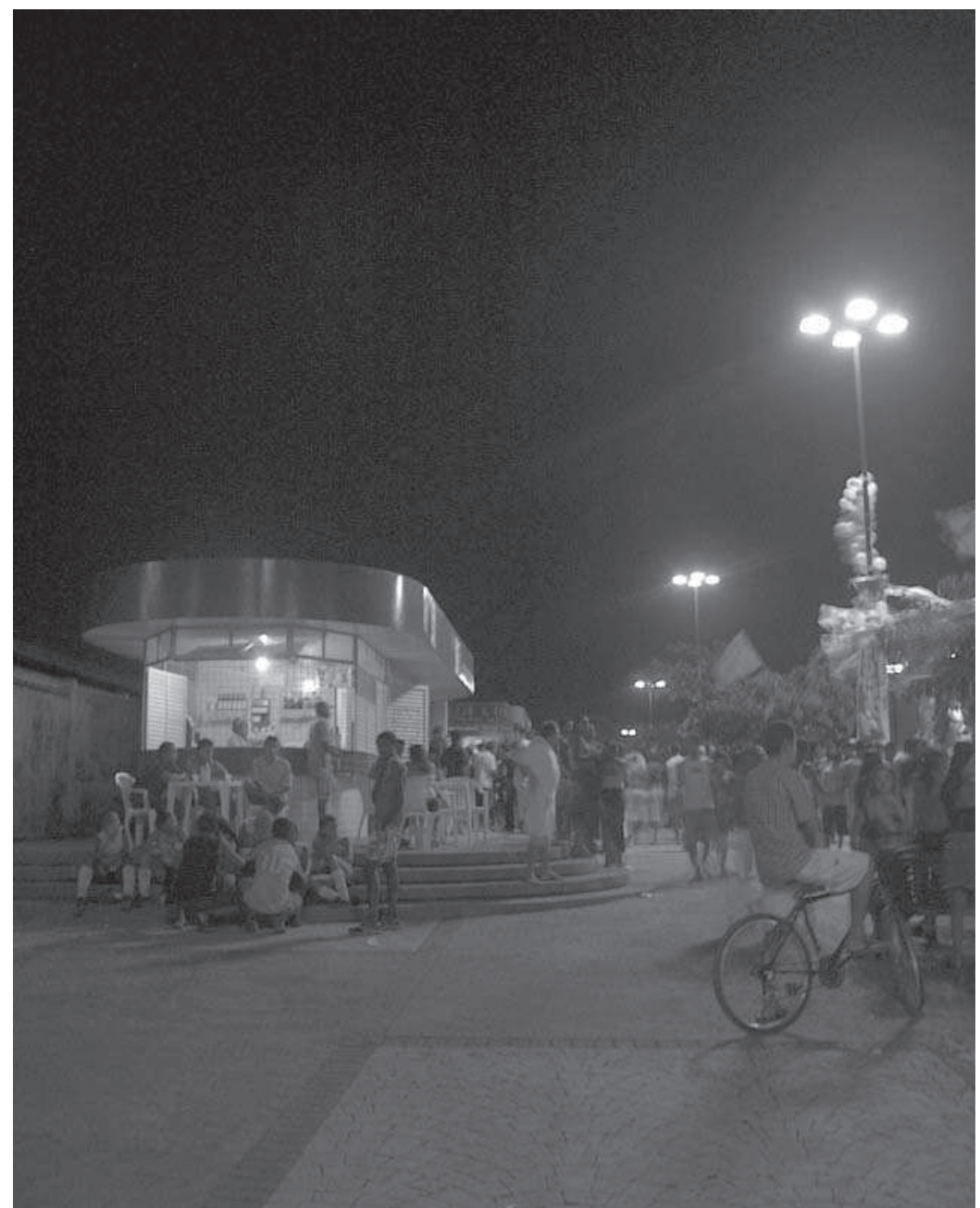

Figura 8: Praça Viva Anjo da Guarda, em São Luís. O que se observa nos programas estudados é que, passados os anos, às vezes poucos meses, o que em geral se mantém íntegro dos projetos é o que eles tinham de melhor para a sociedade

Foto: Francine Sakata, Acervo Quapá/2003

\section{Nota}

(1) Há, até a presente data, somente um curso superior de paisagismo no Brasil, que fica no Rio de Janeiro.

\section{Bibliografia}

ACSEBRAD, Henri (Org.). A duração das cidades: Sustentabilidade e risco nas políticas urbanas. Rio de Janeiro: DP\&A, 2001.

ANDRÈS, Luiz Phelipe de Carvalho Castro (Org.). Centro Histórico de São Luís - Maranhão: Patrimônio mundial. São Paulo: Audichromo Editora, 1998.

BRASILEIRO, Alice de Barros Horizonte. Espaços de uso comunitário em programas habitacionais no Rio de Janeiro: Entre o discurso e a prática. Rio de Janeiro: 2000. Dissertação (Mestrado) - Faculdade de Arquitetura e Urbanismo, Universidade Federal do Rio de Janeiro, 2000.

BONFIM, Juarez Duarte. Políticas públicas para o centro histórico de Salvador: O caso do parque histórico do Pelourinho - Investigação de originalidade numa ação de governo local. 1994. Dissertação (Mestrado em Administração) - Escola de Administração, Universidade Federal da Bahia, 1994.

COUTO, Edgar Tadeu Dias do. Estratégias urbanísticas aplicadas à cidade de São Paulo em um quadro de gestão urbana redemocratizada. 1999. Dissertação (Mestrado) - Faculdade de Arquitetura e Urbanismo, Universidade de São Paulo, 1999. 
FONSECA, Geraldo de Magela. Reintegração urbana de áreas públicas em São Luís com a participação de grupos comunitários: Uma experiência, o programa "Cidade Viva" do Governo Estadual do Maranhão. 2000. Monografia apresentada ao CECl/ MDU, Universidade Federal de Pernambuco e Universidade Estadual do Maranhão, Maranhão, 2000.

GARCIA, Fernanda Éster Sánchez. Cidade espetáculo: Política, planejamento e city marketing. Curitiba: Palavra, 1997.

LEITE, Maria Ângela Faggin Pereira. Uso do território e investimento público. Texto de aula. São Paulo: Faculdade de Arquitetura e Urbanismo da Universidade de São Paulo, São Paulo.

LERNER, Jaime. Acupuntura urbana. Rio de Janeiro: Record, 2003.

LUZ, Ana Maria de Carvalho (Org.). Quem faz Salvador? Salvador: UFBA, 2002.

MACEDO, Silvio Soares. Quadro do paisagismo no Brasil. São Paulo: FAUUSP, 1999.

SAKATA, Francine. Parques urbanos no Brasil. São Paulo: Edusp, 2001.

MAGALHÃES, Roberto Anderson de Miranda. A requalificação do centro do Rio de Janeiro na década de 1990. 2001. Dissertação (Mestrado) - Faculdade de Arquitetura e Urbanismo, Universidade Federal do Rio de Janeiro, Rio de Janeiro, 2001.

MAGALHÃES, Sérgio. Sobre a cidade: Habitação e democracia no Rio de Janeiro. São Paulo: Pro Editores, 2002.

MAIA, César. César Maia. Rio de Janeiro: Editora Rio, 2004.

OLIVEIRA, Marcio de. A trajetória do discurso ambiental em Curitiba (1960-2000). Revista de Sociologia e Política, Curitiba, n. 16, p. 97-106, 2001.

RIO DE JANEIRO (Cidade). Rio Cidade: O urbanismo de volta às ruas. 4. ed. Rio de Janeiro: Iplan, 1991.

Rio Cidade: Ruas livres para pedestres - Linhas gerais projeto urbanístico. Rio de Janeiro: Iplan, s/d.

ROBBA, Fabio. A praça contemporânea nas grandes capitais brasileiras: Do programa à forma projetual. 2004. Tese (Doutorado) - Faculdade de Arquitetura e Urbanismo, Universidade de São Paulo, 2004.

MACEDO, Silvio Soares. Praças brasileiras. São Paulo: Edusp, 2001.

SAKATA, Francine Gramacho. O projeto paisagístico como instrumento de requalificação urbana. 2004. Dissertação (Mestrado) - Faculdade de Arquitetura e Urbanismo, Universidade de São Paulo, 2004.

SILVA, Liliane de Araújo. De paisagem a cenário: A construção da atual orla marítima de Salvador. 2002. Dissertação (Mestrado) - Faculdade de Arquitetura e Urbanismo, Universidade Federal da Bahia, 2002. 